\title{
Mobilidade urbana saudável e segregação socioespacial: desafios da aliança entre pesquisa e participação comunitária ${ }^{1}$
}

Health urban mobility and socioespacial segregation: the challenging alliance between research and community participaton

\section{Cristianne Maria Famer Rocha}

Universidade Federal do Rio Grande do Sul - UFRGS - Porto Alegre - Rio Grande do Sul - Brasil

\section{Julio Celso Borello Vargas}

Universidade Federal do Rio Grande do Sul - UFRGS - Porto Alegre - Rio Grande do Sul - Brasil

\section{Luísa Horn de Castro Silveira}

Universidade Federal do Rio Grande do Sul - UFRGS - Porto Alegre - Rio Grande do Sul - Brasil

Resumo: "Mobilidade urbana saudável" é o conceito que trata da forma como a estrutura física das cidades afeta a mobilidade da população e como esta se relaciona com a saúde e o bem-estar coletivos. O artigo busca compartilhar a experiência da realização de uma pesquisa sobre mobilidade urbana saudável na Região Cruzeiro em Porto Alegre (RS) e as vivências e reflexões suscitadas durante a coleta de dados. Para tornar viável a coleta em grande escala no território, através de questionários sobre o tema, se fez necessária a parceria dos pesquisadores com a população local, relação que provocou tensionamentos e adaptações. O texto traz uma descrição analítica das etapas que possibilitaram a coleta no local, utilizando anotações de diário de campo e o relatório de pesquisa como fontes de informação. A partir das reflexões geradas, ressalta-se a importância da participação comunitária em associação com a pesquisa acadêmica na busca de transformações sociais, ainda que, para tanto, barreiras simbólicas precisem ser superadas. Espera-se que este relato permita compartilhar os aprendizados obtidos, que trazem à tona limitações de mobilidade enfrentadas por moradores de bairros marginalizados e o desafio de transpor a segregação social e espacial nos grandes centros urbanos.

Palavras-chave: Saúde da População Urbana. Participação da Comunidade. Segregação Social.

\begin{abstract}
Healthy urban mobility is the concept that deals with how the physical structure of cities affect the mobility of the population and how it relates to collective health and well-being. The article seeks to share the experience of conducting a research on healthy urban mobility in the Cruzeiro Region in Porto Alegre (RS-Brazil) and the experiences and reflections raised during the survey. In order to make viable the large-scale survey in the territory, it became necessary the researchers' partnership with the local population, a relationship that caused tensions and adaptations. The text provides an analytical description of the survey steps, using the field diary and the research report as sources of information. As a result, the importance of community participation in association with academic research in the search for social transformations is highlighted, even though symbolic barriers must be overcomed. We hope, with this report, to share the lessons learned, which show mobility limitations faced by low-income residents and the challenge of transposing social and spatial segregation in large urban centers.

Keywords: Urban health. Community participation. Social segregation.
\end{abstract}

\footnotetext{
${ }^{1}$ Esse artigo foi produzido durante a realização da Dissertação de Mestrado, intitulada "Rotas interrompidas: (i)mobilidade urbana, saúde e barreiras invisíveis na cidade", junto ao Programa de Pós-Graduação em Saúde Coletiva da Universidade Federal do Rio Grande do Sul.
} 


\section{Introdução}

A mobilidade urbana se refere às condições de deslocamento de uma determinada população no território urbano para exercer suas atividades diárias, que dependem tanto das possibilidades dos grupos populacionais de transitarem pelo espaço da cidade (em termos econômicos e de capacidade física, por exemplo), quanto da infraestrutura oferecida pela cidade para facilitar esse trânsito (ARAÚJO et al., 2001). Atualmente, a mobilidade urbana é um dos problemas mais discutidos globalmente, na medida em que as cidades, em diferentes partes do mundo, têm se expandido e adensado de forma rápida e descontrolada, criando congestionamentos, dificuldades no uso dos espaços públicos e poluição no ar pelo excesso de veículos motorizados (WESTPHAL; OLIVEIRA, 2015). Tornou-se, portanto, tema central na discussão do impacto do desenvolvimento urbano na qualidade de vida da população, que tem particular efeito nos bairros periféricos, pois sistemas de mobilidade ineficientes refletem na desigualdade socioespacial (CARVALHO, 2016).

O intenso crescimento urbano no Brasil, a partir da década de 1960, resultou em sistemas de mobilidade de baixa qualidade e alto custo, prejudicando a vida das pessoas em vários aspectos. Um deles é a supressão ou diminuição do deslocamento quando o nível tarifário do transporte público é alto em relação ao poder aquisitivo da população - resultando em imobilidade e exclusão social (VASCONCELLOS; CARVALHO; PEREIRA, 2011). A má qualidade do transporte público e as longas viagens para chegar de um ponto a outro das cidades tornam-se um incentivo para a utilização de automóveis individuais. No Brasil, nos últimos anos, o aumento do número de veículos automotores (automóveis e motocicletas) foi dez vezes maior que o aumento da população (ARAÚJO et al., 2011). No entanto, ao invés de facilitar a mobilidade, o aumento excessivo de automóveis no ambiente urbano causa, entre outros malefícios, a intensificação do congestionamento $e$, consequentemente, eleva $o$ tempo de deslocamento nas viagens cotidianas. Isso está diretamente associado à qualidade de vida das pessoas, pois o tempo gasto em deslocamento significa perder tempo para outras atividades fundamentais, como lazer e esporte (CRUZ; CALLEJAS; SANTOS, 2014), além do estresse, fadiga e desgaste psicológico envolvidos.

Nesse contexto, uma das preocupações mundiais nas últimas décadas tem sido o aumento do sedentarismo das populações urbanas. As atividades físicas foram desconectadas das atividades diárias, transformando-se em uma opção individual que alimenta um mercado lucrativo e pouco acessível para uma grande parcela da população, que não pode arcar com os custos ou dedicar o tempo e energia necessários para esse fim. Uma solução para esse problema seria reorganizar as áreas urbanas de forma a atrair o tráfego de pedestres e estimular a utilização de meios de transporte não motorizados, o que transformaria a cidade em um espaço de convívio, aumentaria a qualidade de vida e reduziria os gastos em saúde (GEHL, 2015). A utilização do deslocamento ativo é uma tendência que vem se difundindo ao redor do globo. Estudos nos Estados Unidos e Reino Unido apontam que o uso de caminhada ou bicicleta como meio de locomoção está associado à redução da obesidade e do risco de desenvolvimento de doenças como diabetes $\mathrm{e}$ hipertensão (CRUZ; CALLEJAS; SANTOS, 2014).

A exemplo dos estudos citados acima, grande parte das discussões sobre a interface entre mobilidade urbana e saúde diz respeito à saúde física, no que tange os problemas derivados do sedentarismo e da poluição, além dos riscos relacionados aos acidentes de trânsito, o que reflete nas, ainda, poucas políticas intersetoriais existentes. Em 2011, por exemplo, no Plano Nacional de Saúde (2011 - 2015), as principais ações intersetoriais entre setores de planejamento urbano e saúde eram as voltadas para a prevenção de acidentes no trânsito e incentivo à atividade física, com destaque para programas e projetos como o Programa Academia da Saúde e o Projeto Vida no Trânsito (MALTA et al, 2014). Contudo, essa visão ainda permanece focada 
nas doenças e agravos, quando é importante lembrar que buscar saúde é questão não só de sobrevivência, mas de qualificação da existência (SANTOS, 1987).

Mesmo que a cidade, a priori, seja um local de livre circulação para seus habitantes, a utilização dos espaços nem sempre ocorre de maneira democrática. O debate sobre o direito à cidade está entremeado pelo entendimento da lógica da localização dos recursos no espaço urbano, sejam eles a moradia, as oportunidades de emprego, os serviços e os equipamentos urbanos (de educação, saúde, lazer, cultura, segurança), entre outros. No documento de suporte para as discussões no Habitat III, ocorrido em 2016, o direito à cidade é colocado como o "coração da Nova Agenda Urbana". Esse conceito é o novo paradigma para a estruturação de uma nova maneira de pensar as cidades e a urbanização, por meio da realização de diretrizes contidas nos acordos internacionais de direitos humanos, dos Objetivos do Desenvolvimento Sustentável (ODS) e do comprometimento com a própria agenda Habitat (MARGUTI, COSTA, GALINDO, 2016).

Ermínia Maricato (2015) utiliza a crise do transporte público brasileiro com um dos exemplos que ilustram a falta de direito à cidade. A supremacia do automóvel e o aumento do preço do transporte público resultam no exílio daqueles que moram na periferia, onde raramente existem equipamentos de saúde, lazer, educação e esporte em mesmo nível que na região central da cidade. A autora ainda ressalta que "nunca é demais lembrar que pobreza e imobilidade é receita para a violência" (MARICATO, 2015, p.45), já que a falta de mobilidade torna a vida das pessoas restrita, pouco estimulante. A segregação socioespacial e a falta de convivência no território, em especial entre grupos culturalmente diferentes, também pode ser considerada uma receita para a violência e para a guerra urbana, na medida em que a cidade perde seus valores de cooperação e reconhecimento do outro (KUSTER; PECHMAN, 2014). Desse modo, o contraste gerado pela divisão do espaço de acordo com o status econômico dos habitantes afeta o modo como esses grupos convivem entre si, ao ponto de não se reconhecerem como cidadãos de um mesmo território. Forma-se assim, um ambiente de permanente conflito que causa efeitos na saúde dos sujeitos.

A disputa pelo território da cidade é essencialmente ligada às desigualdades econômicas e sociais de seus habitantes. Como visto, a mobilidade ineficiente reforça os processos de exclusão e segregação urbana. No entanto, propomos o seguinte questionamento: se a cidade fosse planejada de acordo com todos os preceitos citados na literatura, com um padrão ideal mobilidade urbana (equitativo, sustentável, inclusivo, etc), quais seriam os dispositivos criados pela própria sociedade para a manutenção dessa segregação? Foucault (1978) nos alertava que a exclusão de certos grupos sociais é um jogo que se atualiza constantemente, mudando os sentidos e as formas de acordo com a cultura e o momento histórico. Também se pode pensar que a aplicação das políticas e práticas recomendadas pode ser dificultada por certos mecanismos e forças, alimentados por ações e situações cotidianas. Por essa razão, torna-se importante também perceber algumas barreiras simbólicas presentes no campo da mobilidade urbana e pensar possíveis modos de superá-las.

Com o objetivo de estudar as condições de mobilidade urbana saudável em três cidades brasileiras (Brasília, Florianópolis e Porto Alegre) e uma cidade do Reino Unido (Oxford), no ano de 2016, iniciamos a realização de um projeto de pesquisa, intitulado Health Urban Mobility/Mobilidade Urbana Saudável (HUM/MUS), que articula o encontro entre as áreas da saúde e do planejamento urbano. Nossa intenção, com esse texto, é compartilhar a experiência da realização da pesquisa sobre mobilidade urbana saudável na Região Cruzeiro em Porto Alegre (RS) e problematizar barreiras simbólicas existentes na relação entre academia e comunidade. A seguir, no percurso metodológico, apresentaremos com maiores detalhes o Projeto HUM/MUS e as nossas estratégias metodológicas para descrever e analisar, aqui, como as experiências suscitadas sugerem reflexões relacionadas com 0 tema da mobilidade urbana saudável e da 
segregação socioespacial, em associação com os desafios de aproximar pesquisa e participação comunitária.

\section{Percurso metodológico}

Esse artigo consiste em um relato de experiência de caráter analítico e reflexivo. As informações foram produzidas a partir de registros no diário de campo da autora principal e do Relatório Parcial das Atividades Realizadas no período de 22 de dezembro de 2015 a 21 de junho de 2017, elaborado pela equipe brasileira da pesquisa HUM/MUS.

O Projeto HUM/MUS é uma pesquisa de cooperação internacional cujo objetivo é estudar as condições de mobilidade urbana saudável em três cidades brasileiras (Brasília, Florianópolis e Porto Alegre) e uma cidade do Reino Unido (Oxford). Em cada uma dessas quatro cidades, foram selecionadas duas vizinhanças de baixa renda e uma de média renda. $\mathrm{O}$ estudo foi feito utilizando-se um questionário em profundidade, aplicado na residência dos participantes, abordando suas impressões sobre o bairro, comportamentos de viagem, atitudes em relação a diferentes meios de transporte disponíveis, além de hábitos de saúde, dados epidemiológicos e aferição de medidas antropométricas (altura, cintura, peso e pressão arterial). Em Porto Alegre, foram realizadas mais de 300 entrevistas em cada uma das vizinhanças selecionadas.

Além de compreender o impacto da (i)mobilidade sobre a saúde e o bem estar desses grupos sociais, outra meta do projeto diz respeito à participação comunitária. A intenção é, a partir do levantamento realizado, explorar o potencial de planejamento de mobilidade participativo com as comunidades locais, para apoiar e desenvolver soluções de mobilidade para as regiões do estudo. Pretende-se, então, que no desfecho do Projeto, a ser realizado no segundo semestre de 2018, sejam utilizados os resultados da pesquisa, ainda em fase de análises, para promover melhorias, com apoio dos moradores, através de um conselho ou grupo de trabalho formado para esse fim.

Alguns critérios foram definidos para a escolha das áreas de estudo, após visitas in loco nas quatro cidades. Todas as vizinhanças escolhidas estão a menos de dez quilômetros das áreas centrais da cidade e as duas vizinhanças de baixa renda se diferenciam da seguinte forma: uma delas se caracteriza por um traçado urbano formal (padrão uniforme de quarteirões retangulares) e outra informal (geometria típica de assentamento informal com traçado irregular). Ambas as vizinhanças de baixa renda, em Porto Alegre, fazem parte da mesma região, denominada Grande Cruzeiro, que é conhecida pela população como um local de confronto entre facções do tráfico. Está entre as piores regiões nos indicadores relacionados ao número de pessoas morando em condições de favela e à desigual distribuição de renda, além de ser a quarta com maior taxa de homicídios, de acordo com o Censo de 2010 (PORTO ALEGRE, 2017).

O Projeto HUM/MUS foi avaliado, em Porto Alegre, pelo Comitê de Ética em Pesquisa da Secretaria Municipal de Saúde (CEP/SMS), sob o Certificado de Apresentação para Apreciação Ética (CAAE) de número 58214416.9.3001.5338. Todos os entrevistados foram convidados a assinar um Termo de Consentimento Livre e Esclarecido (TCLE). A garantia de confidencialidade das informações fornecidas, assim como o caráter voluntário da participação e o direito de retirar-se da pesquisa a qualquer momento são explicitados no Termo.

\section{Análise crítica da experiência}

Antes de iniciar a coleta do Projeto HUM/MUS, houve uma importante etapa de preparação e aproximação com o campo. Muitas experiências interessantes surgiram desse encontro inicial, assim como situações inesperadas e saberes adquiridos conforme se foi avançando na realização do estudo. Os serviços do Sistema Único de Saúde (SUS) de Porto Alegre são distribuídos em dezessete Distritos Sanitários e organizados pelas Gerências Distritais de 
Saúde (GDS) (PORTO ALEGRE, 2017). Para tornar viável a coleta de dados na Região Cruzeiro, a equipe HUM/MUS Porto Alegre buscou estabelecer uma parceria com trabalhadores da saúde locais, entrando em contato com a GDS da Região. Tal iniciativa teve como objetivo analisar, em conjunto com trabalhadores, qual a melhor forma de realizar a pesquisa de campo, considerando-se as particularidades do território. Duas frentes de trabalho se criaram a partir desses encontros: estratégias de divulgação da pesquisa e recrutamento de entrevistadores.

Iniciou-se uma ampla divulgação da pesquisa na Região Cruzeiro, em que os pesquisadores participaram de reuniões do Conselho Local de Saúde e de eventos comunitários, trazendo materiais para distribuição com a logomarca da pesquisa. O desenvolvimento dessa logomarca foi feito com apoio da equipe britânica do Projeto, para dar uma identidade visual ao mesmo. A ideia de ter uma imagem vinculada à pesquisa era de despertar a curiosidade sobre o que os pesquisadores estavam fazendo no local e, consequentemente, sobre o tema da mobilidade urbana saudável, visto que esse ainda não é um conceito popularizado. Desejava-se que, antes de os moradores serem convidados a responder perguntas sobre seus hábitos de mobilidade, eles já tivessem tido algum contato com o tema. A popularização do saber científico é uma preocupação que permeia a execução da pesquisa HUM/MUS, que está de acordo com a ideia de que "o desejo da ciência (empírica, hermenêutica e social crítica) é de que seu produto seja o mais possível espalhado, socializado e acessível para todas as camadas da população" (SILVA; NETO, 2015, p. 146).

Outro objetivo dessa etapa de divulgação era que, quando os pesquisadores começassem a percorrer o território, identificados com o colete da pesquisa, a população já estivesse familiarizada com o estudo - o que poderia aumentar a sensação de segurança tanto dos participantes, quanto dos entrevistadores. Por ser um local considerado inseguro, a GDS recomendou que os pesquisadores andassem sempre identificados, para que os moradores sentissem mais confiança na presença de pessoas desconhecidas circulando pelas ruas. Interessante perceber o quão contrastante é, para a comunidade, essa característica de ser de dentro ou de fora do bairro, o que se pode entender como uma denúncia da segregação socioespacial existente na cidade. Supõe-se, de um modo geral, que não há circulação de pessoas que não sejam moradoras da região, a não ser para fazer pesquisa ou por objetivos que despertem receio e desconfiança. O uso do colete também pode ser entendido como uma barreira simbólica, visto que o colete utilizado é branco e, mesmo que a logomarca colorida da pesquisa esteja impressa na frente, a cor branca remete aos jalecos utilizados por profissionais da saúde - que servem para diferenciar profissionais de usuários, gerando distanciamentos.

Para desconstruir a divisão simbólica entre pesquisadores e participantes de pesquisa, a equipe decidiu selecionar, inicialmente, entrevistadores exclusivamente dentre os moradores da região. Além de minimizar esse fator, a intenção também foi contar com o conhecimento do morador local como um facilitador para a abordagem nas residências. A GDS divulgou a seleção nas unidades de saúde e ficou responsável por fazer uma primeira "seleção" dos candidatos, de acordo com critérios préestabelecidos: pessoas que tivessem um histórico de participação em assuntos comunitários e boa desenvoltura e habilidades de comunicação. Pareceu interessante selecionar Agentes Comunitários de Saúde (ACS), já que essa profissão tem atributos que seriam úteis para a pesquisa, como a prática em fazer visitas domiciliares e conhecimento do território. Dessa forma, o time de entrevistadores que iniciou a coleta era composto majoritariamente por ACS da Região.

O grupo de ACS selecionado para realizar a coleta de dados era bastante participativo. Durante a oficina de formação dos entrevistadores, em que se apresentou o instrumento de coleta, eles contribuíram criticamente, pedindo adequações em relação à linguagem utilizada nas perguntas, por exemplo. Para 
eles, alguns enunciados eram confusos ou não faziam sentido, o que permitiu que a equipe de pesquisadores (re)pensasse o significado de alguns pontos do questionário, que não haviam sido observados em profundidade, auxiliando a torná-los mais palpáveis na hora de aplicá-los. Também foi interessante observar a troca interdisciplinar que ocorreu com os ACS, que compartilharam das suas experiências de trabalho. Uma das entrevistadoras, por exemplo, fez uma adaptação na ordem do questionário, fazendo a aferição da pressão arterial no início, de modo a permitir que a pessoa se sentisse à vontade para tomar café ou chimarrão durante a entrevista sem alterar o resultado da medida. Tal mudança de protocolo, amparada pela experiência da ACS, nos possibilitou perceber a pertinência da sugestão, ainda que muitas vezes existam tensões e receios na troca entre conhecimento científico e saber popular, já que este pode ser visto como algo pouco confiável e dominado pelo senso comum (SILVA; NETO, 2015). No caso da pesquisa em questão, deve-se levar em conta que os ACS são também trabalhadores da saúde o que, talvez, tenha contribuído para que essas intervenções fossem acolhidas com mais facilidade pelos pesquisadores.

As diferenças sociais e econômicas se materializam no espaço urbano, pois a localização das atividades no território e as condições que esse território apresenta dependem do poder dos grupos sociais que nele residem: "grupos elitizados e dominantes têm maior liberdade de escolha de localização em relação às oportunidades que o território apresenta e usufruem mais vantagens locacionais" (FERREIRA; VASCONCELOS; PENNA, 2008, p. 3-4). Dessa forma, ocorre uma injustiça espacial, já que quem tem mais dificuldade de acesso a oportunidades do ponto de vista econômico e social fica também espacialmente afastado delas, o que só confirma e reforça essas diferenças sociais. A Região Cruzeiro, mesmo tendo uma localização próxima do centro, não possuiu atrativos e atividades relevantes que promovam uma interlocução com o resto da cidade, transformando-a num espaço separado, ou segregado, do entorno. A sensação de isolamento permeia a fala dos moradores da Região, quando conversamos sobre mobilidade urbana. Até o sistema de transporte público parece reforçar essa realidade, pois, apesar de a Região estar em uma localização privilegiada (próxima ao Centro, ao Lago Guaíba e a outros pontos de referência da cidade), parece difícil deslocar-se dali para esses locais. A oferta de ônibus, dependendo do ponto em que se está no bairro, permite que se vá até o centro, mas se há o desejo de ir a outras partes da cidade, é necessário tomar dois ônibus, fazendo com que distâncias curtas pareçam imensas para quem utiliza esse tipo de transporte. Além disso, esse assunto traz à tona diferenças já normalizadas no contexto urbano, como a melhor qualidade dos ônibus que circulam nas regiões mais valorizadas da cidade e o descaso do poder público na manutenção e qualificação da infraestrutura de regiões como a Cruzeiro.

Quando os ACS entraram em campo para começar a coleta, um primeiro retorno recebido foi de que as ruas e vias selecionadas eram de difícil acesso, mesmo para quem está habituado com o bairro. Uma das entrevistadoras, inclusive, mencionou que gostaria de ter participado da fase de amostragem, ou seja, auxiliado os pesquisadores a escolher os pontos do mapa a serem utilizados na coleta. Com tudo isso, a participação popular que, inicialmente, havia sido prevista no Projeto como um desfecho, passou a ser entendida pela equipe como uma meta transversal, que poderia ter sido incentivada, inclusive, antes mesmo da escolha das áreas de coleta. Certamente, a principal dificuldade da coleta de dados foi exatamente em relação à escolha das áreas, pois os pesquisadores não tinham conhecimento prévio sobre onde se encontravam os locais de risco existentes na Região Cruzeiro. A presença do tráfico de drogas, com seus violentos embates entre grupos rivais, é vivida cotidianamente pelos moradores e as dificuldades de mobilidade resultantes disso foram sentidas pelos pesquisadores também. Foi necessário fazer um verdadeiro jogo de quebra-cabeças com os mapas, para que pudéssemos garantir a coleta sem alterar os critérios 
estabelecidos anteriormente e, principalmente, sem colocar nenhum membro das equipes em risco. Pensou-se que o deslocamento dos entrevistadores seria mais fácil por eles serem moradores do bairro, mas, foi o contrário. O fato de eles serem conhecidos impedia que eles acessassem certas áreas, pois há uma disputa de território entre as lideranças do tráfico: quando um morador de uma área dominada por um grupo entra na área dominada pelo outro, isso não é visto com bons olhos. Assim, o trabalho dos entrevistadores foi dificultado por esses bloqueios inesperados.

A ampliação das atividades criminosas no interior das favelas está relacionada com a expansão do narcotráfico após a crise econômica na década de 1980 e foi se agravando ao longo dos anos:

(...) entre 2003 e 2009, a violência nessas áreas, relacionada ao tráfico de drogas e às milícias, alcançou níveis intoleráveis. $\mathrm{Na}$ medida em que os espaços públicos foram privatizados pelos narcotraficantes, deixaram de ser seguros para os moradores, que passaram a viver receosos de serem atingidos durante tiroteios entre quadrilhas rivais ou entre policiais e traficantes (GOMES; FERNANDES; FRANÇA, 2013, p. 24).

As periferias oferecem uma localização privilegiada para o estabelecimento do crime, tanto pela ausência de segurança pública, quanto por fatores geográficos e espaciais, como os labirintos formados por entre as casas, que facilitam a circulação de substâncias ilícitas e eventuais fugas da polícia (FERREIRA; VASCONCELOS; PENNA, 2008; GOMES; FERNANDES; FRANÇA, 2013). A mobilidade da população local fica bloqueada por esses territórios dominados pelo crime, como pudemos ver na Região Cruzeiro.

Esse problema foi um dos fatores, reportados pelos trabalhadores, que levou à desistência de quase todos os entrevistadores que iniciaram a coleta. A chegada do inverno, quando anoitece mais cedo, também foi apontada como um transtorno que impediria a produtividade desejada. Como quase todos eram trabalhadores das Unidades de Saúde, sobrava o turno pós-expediente para que eles pudessem se dedicar à pesquisa, mas à noite muitas das ruas que haviam sido selecionadas para a coleta não tinham iluminação, tornando inviável a circulação de pedestres. Mais uma vez, percebeu-se que, ironicamente, a Cruzeiro apresenta problemas de mobilidade tão intensos que dificultam, inclusive, a realização de uma pesquisa sobre o tema no local. Foi preciso fazer uma nova seleção de entrevistadores, que tivessem disponibilidade para trabalhar no período diurno, ainda que não moradores da Região. Dessa forma, com o tempo, o grupo inicial de entrevistadores foi se modificando. Chamamos estudantes de graduação e pós-graduação para reforçar a equipe, formando um grupo misto. Ao final da coleta nas áreas da Cruzeiro, fizemos uma pausa e uma nova contratação de entrevistadores para iniciar os trabalhos no bairro de renda média, mas nenhum dos trabalhadores que moravam na Região Cruzeiro se interessaram em fazer parte desse novo grupo.

Revisitando o diário de campo, tentamos elaborar compreensões sobre esse fenômeno de desistências e de gradual "academicização" do grupo de entrevistadores da pesquisa. O entusiasmo inicial por tentar diminuir o distanciamento entre saber científico e saber popular, rompendo barreiras entre pesquisadores e participantes de pesquisa, a partir desse trabalho em conjunto, foi diminuindo com o passar dos meses. No lugar do entusiasmo, sentimentos de frustração e incômodo permeavam as conversas da equipe fixa do Projeto, ao nos depararmos com a dificuldade de promover um maior engajamento desses trabalhadores na pesquisa. As barreiras simbólicas entre comunidade e academia que pensávamos estar transpondo - se adensaram ao passo em que avançávamos, talvez pela expectativa de despertar o interesse acadêmico na população local. Expectativa baseada unicamente nos nossos próprios parâmetros e desejos.

Ficamos presos à nossa própria forma de pensar, pois vivemos presos, apartados da diferença. Para além de uma questão do uso do espaço e de acesso a direitos, a segregação representa um distanciamento de mundos em que os modos de vida se diferem e nos quais as pessoas são subjetivadas. 
Segundo Luis Antonio Baptista (1999), esse apartheid urbano solidifica e afirma a construção de identidades que moralizam e patologizam o diferente. Mas, mais do que simplesmente estranhar a alteridade, fica evidente a tentativa de disciplinamento de corpos empregada nas relações entre os personagens dessa experiência. $\mathrm{O}$ estranhamento da alteridade ilustra 0 como somos subjetivados de modos diferentes, dentro dessas divisões de espaços, onde os sujeitos são dispostos no tecido social - "A Academia" e "A Comunidade" são espaços simbólicos, mas também geográficos da cidade. O disciplinamento se dá nas relações cotidianas, nas tentativas de normalização do outro que escapa das formatações às quais estamos habituados. São relações de poder que nós mesmos renovamos a todo instante, fazendo-as funcionar não de cima para baixo, mas na própria trama da multiplicidade (FOUCAULT, 1987). Mesmo com a melhor das intenções - de tentar respeitar as diferenças -, acabamos tentando trazer os sujeitos o mais próximo possível da nossa forma de funcionar nossos modelos de produção, nossas percepções sobre horários e tempos, nossas formas de contrato. Tudo isso colidia e se ajustava em um movimento contínuo de atualização dessa interação, ao mesmo tempo em que a coleta de dados (por si só exaustiva e cheia de imprevistos) acontecia. Talvez por isso, ao fim de sete meses de coleta na Cruzeiro, o cansaço era imenso e a vontade de distanciamento inegável.

Felizmente, a parceria criada com os agora "ex-entrevistadores" também permaneceu, de modo que os pesquisadores-estudantes se reportavam a eles quando se fez necessário obter informações e recomendações quanto às amostras refeitas. Criouse, dessa maneira, informalmente, uma espécie de "conselho de assuntos locais", composto pelos ACS que tinham iniciado a coleta de dados e algumas lideranças que se aproximaram da pesquisa através deles. Esse grupo de pessoas foi, também, responsável por oferecer um local para as reuniões semanais de monitoramento, que passou a ocorrer sempre em um Centro Comunitário da Região. É perceptível o quanto a relação entre pesquisadores e comunidade se modificou após a adoção/utilização desse local, pois, de certo modo, ocorreu uma inversão da ordem estabelecida: a comunidade estava oferecendo algo à Universidade e não o oposto, como costuma acontecer. Acredita-se que essa inversão provocou maior engajamento dos colaboradores locais.

Ao longo da coleta de dados, muitas modificações e adaptações precisaram ser feitas, porém algo foi ficando evidente: a potência dos espaços de troca com a comunidade. As reuniões semanais de monitoramento e outros encontros, como algumas oficinas e workshops realizados, tornaram-se espaços de formação para todos os colaboradores envolvidos, moradores e não moradores da Região. Ao mesmo tempo em que a equipe de pesquisa foi se qualificando (a respeito do território, seus habitantes e relações com a mobilidade urbana), a comunidade também se beneficiou, ao agregar ao seu rol de saberes um novo leque de perspectivas sobre o tema da pesquisa: planejamento urbano e seus impactos na saúde. Apesar de todas as dificuldades relatadas, esse aprendizado coletivo é, certamente, muito maior do que se fossem apenas apresentados os resultados da pesquisa à comunidade ou se a pesquisa fosse realizada sem a potente interlocução realizada entre equipe e moradores.

\section{Considerações finais}

A escolha de selecionar moradores da comunidade para serem entrevistadores mostrou-se uma estratégia chave na pesquisa HUM/MUS em Porto Alegre, assim como a parceria com trabalhadores da saúde da Região e lideranças comunitárias. Essa decisão gerou muitos desafios, mas foi um processo rico, que ampliou os objetivos de participação cidadã previstos no Projeto, além de provocar novos olhares sobre temas importantes para a área de estudo, tal como a segregação socioespacial. A diminuição da distância entre saber científico e popular pode ser uma via de combate a essa segregação, visto que gera uma aproximação da comunidade com os debates de interesse acadêmico 
e enriquece a pesquisa com assuntos de interesse local. No entanto, é preciso estar atento às tentativas de disciplinamento e adaptação aos modos de pensar típicos do universo acadêmico, para que seja uma relação de troca minimamente democrática.

A Região Cruzeiro apresenta profundos problemas de mobilidade, a exemplo de muitas periferias urbanas a nível global. Destaca-se a questão da violência e do domínio do narcotráfico como principal barreira para o livre trânsito dos moradores no território, o que impacta drasticamente no seu bem-estar. A segregação socioespacial também é visível e preocupante, na medida em que os moradores têm menos direito às oportunidades oferecidas pela cidade e não há investimento local para que a Região proporcione atrativos para valorização da comunidade.

Diante disso, é preciso enfatizar a importância do incentivo à participação popular nas decisões políticas de interesse social. A pesquisa HUM/MUS almeja, para os próximos passos do Projeto, ser um canal de comunicação entre a população da Região estudada e as instâncias responsáveis pelo planejamento urbano da cidade, de forma a endereçar as questões levantadas pelo estudo. Espera-se que a aliança que vem se consolidando com a comunidade auxilie na criação de espaços de discussão e tensionamento, com vistas à efetivação das melhorias necessárias para aumentar o potencial de mobilidade urbana saudável na Região Cruzeiro.

\section{Referências}

ARAÚJO, M. R. M. et al. Transporte público coletivo: discutindo acessibilidade, mobilidade e qualidade de vida. Psicologia \& Sociedade, Florianópolis, v. 23, n. 3, p. 574-582, dez. 2001.

BAPTISTA, L. A. Cidade dos Sábios: Reflexões sobre a dinâmica social nas grandes cidades. São Paulo: Summus, 1999.

CARVALHO, C. H. R. Mobilidade Urbana: avanços, desafios e perspectivas. In: Costa, M. A. (Org.). O Estatuto da Cidade e a Habitat III: um balanço de quinze anos da política urbana no
Brasil e a Nova Agenda Urbana. Brasília: IPEA, 2016, p. 345-361.

CRUZ, S. R. S.; CALLEJAS, A. G. H.; SANTOS, M. Em busca de cidades ativas: a prática da corrida como mobilidade urbana. Revista de Cultura e Extensão USP, São Paulo, n. 12, p. 67-81, nov. 2014

FERREIRA, I. C. B.; VASCONCELOS, A. M. N.; PENNA, N. A. Violência Urbana: a vulnerabilidade dos jovens da periferia das cidades. In: Encontro Nacional de Estudos Populacionais, 16., 2008, Caxambu, MG. Anais eletrônicos...Caxambu: ABEP, 2008. p. 1-18. Disponível em: <http://www.abep.org.br/publicacoes/index.php/ anais/issue/view/36/showToc>. Acesso em: 20 ago. 2017.

FOUCAULT, Michel. História da loucura na Idade Clássica. Tradução: José Teixeira Coelho Netto. São Paulo: Editora Perspectiva, 1978.

FOUCAULT, Michel. Vigiar e punir: nascimento da prisão. Tradução: Lígia M. Pondé Vassallo. 5. ed. Petrópolis: Vozes, 1987.

GEHL, J. Cidades para pessoas. São Paulo: Perspectiva; 2015

GOMES, M. F. C. M.; FERNANDES, L. L.; FRANÇA, B. A. Dinâmicas de uma cidade em transformação: urbanização, segurança pública e tráfico de drogas no Rio de Janeiro. In: GOMES, M. F. C. M.; MAIA, R. S.; CARDOSO, I. C. C.; FRANÇA, B. A. Renovação urbana, mercantilização da cidade e desigualdades socioespaciais. Rio de Janeiro: Mauad; 2013. p. $19-36$

KUSTER, Eliana; PECHMAN, Robert. O chamado da cidade: ensaios sobre a urbanidade. Belo Horizonte: Editora Ufmg, 2014.

MALTA, D. C. et al. A implementação das prioridades da Política Nacional de Promoção da Saúde, um balanço de 2006 a 2014. Ciência \& Saúde Coletiva, Rio de Janeiro, v. 19, n. 11, p. 43014311, nov. 2014

MARICATO, E. Para entender a crise urbana. São Paulo: Expressão Popular, 2015.

MARGUTI, Bárbara Oliveira; COSTA, Marco Aurélio; GALINDO, Ernesto Pereira. A trajetória brasileira em busca do direito à cidade: os quinze anos de estatuto da cidade e as novas perspectivas à luz da nova agenda urbana. In: COSTA, Marco Aurélio. O Estatuto da Cidade e a Habitat III: um balanço de quinze anos da política urbana no Brasil e a nova agenda urbana. Brasília: Ipea, 2016. p. 11-25.

PREFEITURA MUNICIPAL DE PORTO ALEGRE. Observa POA. Disponível em: 
$<$ http://www.observapoa.com.br/>. Acesso em: 20 ago. 2017.

PREFEITURA MUNICIPAL DE PORTO ALEGRE. SMS: Estrutura. Disponível em: <http://www2.portoalegre.rs.gov.br/sms/> Acesso em: 20 ago. 2017

SANTOS, B. S. Um Discurso sobre as Ciências. Porto: Afrontamento, 1987.

SILVA, S. F.; NETO, J. F. M. Saber popular e saber científico. Revista Temas em Educação, João Pessoa, v. 24, n. 2, p. 137-154, jul./dez. 2015.

VASCONCELLOS, E. A.; CARVALHO, C. H. R.; PEREIRA, R. H. M. Transporte e mobilidade urbana. Brasília: CEPAL - IPEA, 2011.

WESTPHAL, M. F.; OLIVEIRA, S. C. Cidades Saudáveis: uma forma de abordagem ou uma estratégia de ação em saúde urbana? Revista USP, São Paulo, n. 107, p. 91-102, out./dez. 2015. 